\title{
Antenatal Tanılı Turner Sendromunda Bilateral Renal Agenezi ve Aort Stenozu
}

Bilateral Renal Agenesis and Aortic Stenosis in an Antenatally Diagnosed Turner Syndrome

\author{
Handan Hakyemez TOPTAN ${ }^{1}$, Nilgün KARADAĞ ${ }^{1}$, Abdülhamit TÜTEN ${ }^{1}$ \\ Tülin Gökmen YILDIRIM ${ }^{1}$, Gülsen AKAY ${ }^{\text {, }}$, Mehmet Burak MUTLU ${ }^{3}$, Güner KARATEKİN ${ }^{1}$ \\ 1. Zeynep Kamil Kadın Doğum ve Çocuk Hastalıkları Eğt. Arş. Hast., Yenidoğan Yoğun Bakım Ünitesi, İstanbul \\ 2. Zeynep Kamil Kadın Doğum ve Çocuk Hastalıkları Eğitim Araştırma Hastanesi, Çocuk Genetik Bölümü, İstanbul \\ 3. Zeynep Kamil Kadın Doğum ve Çocuk Hastalıkları Eğitim Araştırma Hastanesi, Tıbbi Genetik Bölümü, Istanbul
}

\section{$\ddot{O Z E T}$}

Turner sendromu X kromozomunun birinin kaybı veya yapısal anomalisi ile karakterize kromozomal bir bozukluktur. Vakaların önemli bir bölümü abortus ile sonuçlanmaktadır. Klinik bulguları yenidoğan döneminde her zaman görülmeyebilir. Bu nedenle sonraki yaşlarda tanı alabilirler. Turner sendromu el ayak sirtında lenf ödem, düşük ense saç çizgisi, klsa yele boyun gösteren hastalarda düşünülmelidir. Bu sendroma kardiyovasküler, genitoüriner ve endokrin sistem anomalileri siklıkla eşlik edebilmektedir. Bu olgu sunumunda bilateral renal agenezi, pulmoner hipoplazi ve aort stenozunun eşlik ettiği antenatal tanılı bir Turner sendromu olgusu sunulmuştur.

Anahtar Kelimeler: Aort stenozu; Renal agenezi; Turner sendromu

\section{ABSTRACT}

Turner syndrome is a genetic disorder caused by loss or structural disorders of X chromosome. A significant number of cases result with abortion. Clinical symptoms are not always apparent in the newborn period. Therefore it could be diagnosed in later years of life. Turner syndrome should be considered in patients with lymphedema on hands and feets, low hairline, short and webbed neck. Cardiovascular, genitourinary, endocrine system disorders could be accompanied. Here we present an antenatally diagnosed Turner syndrome with bilateral renal agenesis, pulmonary hypoplasia and aortic stenosis.

Keywords: Aortic stenosis; Renal agenesis; Turner syndrome

\footnotetext{
İletişim:

Sorumlu Yazar: Dr. Handan Hakyemez TOPTAN

Adres: Zeynep Kamil Eğitim Araştırma Hastanesi Yenidoğan Yoğun Bakım Ünitesi, İstanbul

Tel: $+90(21 \mathrm{x}) \mathrm{xxx} \mathrm{xx} x \mathrm{x}$

E-Posta: hhandan98@hotmail.com

Makale Geliş: 07.01.2016

Makale Kabul: 02.07.2016

DOI: http://dx.doi.org/10.16948/zktipb.237205
}

\section{GİRIŞ}

Turner sendromu (TS) 2500 canlı kız doğumda bir görülen $X$ kromozomunun birinin kayb1 veya yapisal anomalisi ile karakterize kromozomal bir bozukluktur. Gerçek insidansı hafif fenotipli tanı almamış olgular nedeniyle bilinmemektedir (1). Konsepsiyondaki sıklığ çok yüksek olmasına karşın etkilenen fetusların yaklaşık \%99'u intrauterin kayıpla sonuçlanmaktadır. X monozomisi olan hastalarda $\% 80$ 'ininde $\mathrm{X}$ kromozomunun yalnızca anneden geçtiği gösterilmiştir (2). Boy kısalığı, gonadal yetersizlik, renal ve kardiyak anomaliler, yele boyun, düşük ense saç çizgisi, cubitus valgus ve ayrık meme başı gibi bulgular sendromun başlıca özellikleridir. İlk defa 1938 yılında Henry Turner tarafindan kısa vücut yapısı, yele boyun, seksüel immatürite ve kubitus valgus özelliklerini gösteren yedi kadında tanımlanmiştır (3). Yenidoğan döneminde yele boyun, el ayak sırtında lenf ödem, düşük ense saç çizgisi, tırnak displazisi, yüksek damak, metakarpal kemikte kısalık, meme ucu ayrıklığı, kubitus valgus gibi bulgularla tanı alırken, prepubertal dönemde boy kısalığı, adolesan dönemde bu bulgularla beraber pubertal gecikme nedeni ile incelenme sirasinda tanı konulmaktadır (4). Turner sendromu mortalite oranını 3 kat arttırmakta ve yaşam beklentisini 13 yıl düşürmektedir (5). Kardiyovasküler anomaliler TS'lu hastalarda en önemli mortalite nedenidir. En s1k görülen kalp anomalisi biküspid aort kapağıdır. Aort koarktasyonu, atriyal septal defekt, aort darlığı TS'da görülen diğger sik kalp anomalileridir (6). Burada bilateral renal agenezisi, pulmoner hipoplazisi ve aort stenozu olan antenatal tanılı bir Turner sendromu olgusu sunulmuștur.

\section{OLGU SUNUMU}

Yirmi üç yaşındaki anneden G1P1Y1 olarak sezaryen ile 37 . haftasında 1810 gr doğan kız bebeğin 1./5.dk APGAR'1 5-6 idi. Doğumda spontan solunumu olmayan kalp atımları bradikardik, refleksleri zayıf, hipotonik hastanın 
pozitif basınçl1 ventilasyona cevap vermemesi üzerine entübe edilerek yenidoğan yoğun bakım ünitesine alındı. Gebelik izleminde yapılan ultrason incelemelerinde nukal kalınlık, boy kısalığı, intrauterin büyüme gelișme k1sitlılığ (IUBK) ve displastik böbrek yapısı gösteren hastaya 18. gebelik hastasinda amniyosentez yapılmış. Kromozom analizi incelemesinde TS tanısı almıș. Postnatal dönemde servise kabulünde yapılan fizik muayenesinde atipik yüz görünümü, basık burun kökü, düşük ense saç çizgisi, yele boyun, el ve ayak sırtında belirgin lenf ödemi, meme ucu ayrıklığı, kalkan göğüs yapıs1, hiperekstansibl eklemleri ve kubitus valgusu dikkat çekmekteydi.

Takipnesi ve çekilmesi olan hastanın çekilen akciğer grafisinde pulmoner hipoplazi saptand1. Surfaktan uygulanan mekanik ventilatörde takibe alınan hastaya ilk saatlerde bilateral pnömotoraks saptanması nedeniyle iki taraflı göğüs tüpü takıldı (Șekil 1-2). Oksijen satürasyonları $\left(\mathrm{SaO}_{2}\right)$ yapılan girişimsel işlemlere ve mekanik ventilatör desteğine rağmen \%80'nin üzerine çıkmayan hastaya yapılan ekokardiyografide aort stenozu, aort koarktasyonu, patent duktus arteriosus saptand. Tüm batın ultrasonografi incelemesinde bilateral renal agenezi görüldü. Tansiyonları düşük giden hastaya inotrop olarak dopamin, dobutamin infüzyonu desteği başlandi.

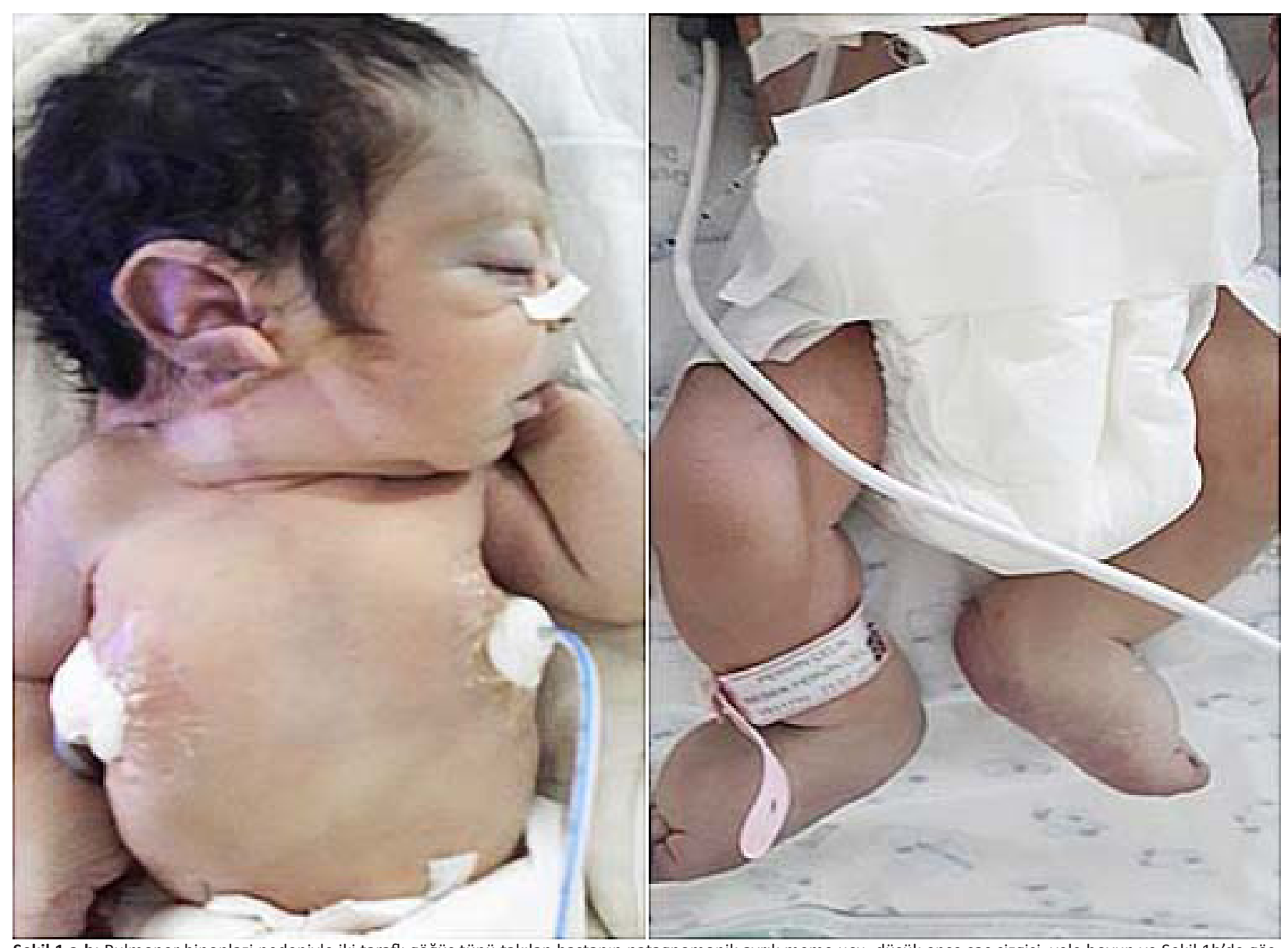

Şekil 1 a-b: Pulmoner hipoplazi nedeniyle iki taraflı göğüs tüpü takılan hastanın patagnomonik ayrık meme ucu, düşük ense saç çizgisi, yele boyun ve Şekil 1b'de gösterilen klasik ayak sırt ödemi görünümü.
İzleminde oksijen saturayonları düsen hastanın çekilen PA akciğer grafisinde bilateral pnömotoraks saptanması üzerine toraks tüpü takıldı. İki gün izlemi sürdürülen hastanın tüm destek tedavilerine rağmen yaşamının 30.saatinde kardiyak arresti gelişti ve kaybedildi. Hastadan yapılan kromozom analizi $45, X$, inv (9) $(\mathrm{p}=11, \mathrm{q}=13)$ olarak rapor edildi.

\section{TARTIŞMA}

Turner sendromu el ve ayak sirtında lenf ödem, düşük ense saç çizgisi, yele boyun gibi fenotipik özellikler belirgin ise yenidoğan döneminde tanı alırken, prepubertal dönemde boy kısalığı, adolesan dönemde ise genellikle pubertal gecikme (meme gelişiminin olmaması, primer amenore) nedeniyle araştırılırken tanı almaktadırlar (3). Vakaların genellikle 1/3'ü yenidoğan döneminde, 1/3'ü çocukluk döneminde, kalan 1/3'ü ise adolesan dönemde tan1 alır (5). Turner sendromu gebelikte tanınabilen bir hastalıktır. Gebelikteki izlemlerde IUBK, nukal kalınlık, boy kısalığı, kalp ve böbrek anomalileri, kistik higroma, gibi ultrason bulguları gösteren fetüslerde TS akla gelmelidir. Bu vakalarda amniyosentez ile kromozom incelemesi yapılması kesin tanı konulmasına yardımcı olur (6). Turner sendromu ayrica farklı yapisal genetik anomalilerle de karşımıza çıabilir. Hastaların \%50'sinde 45, X şeklinde, \%17'sinde X 
kromozomunun uzun kolunun bir izokromozomu bulunur, \%24 vaka mozaiktir, \%7'sinde X kromozomu halka șeklinde ve \%2'sinde X kromozomunun kisa kolunda delesyon vardir. $\mathrm{X}$ kromozomunun k1sa kolunun delesyonu Turner sendromu fenotipi ile ilişkilidir. Uzun kolunun delesyonu daha çok kısa boy ve overyen disgenezisden sorumlu tutulmaktadir $(2,6,7)$. Yenidoğan döneminde hastanın daha önce antenatal tanısı yok ise TS tanısını klinik olarak koymak her zaman kolay olmamaktadir.

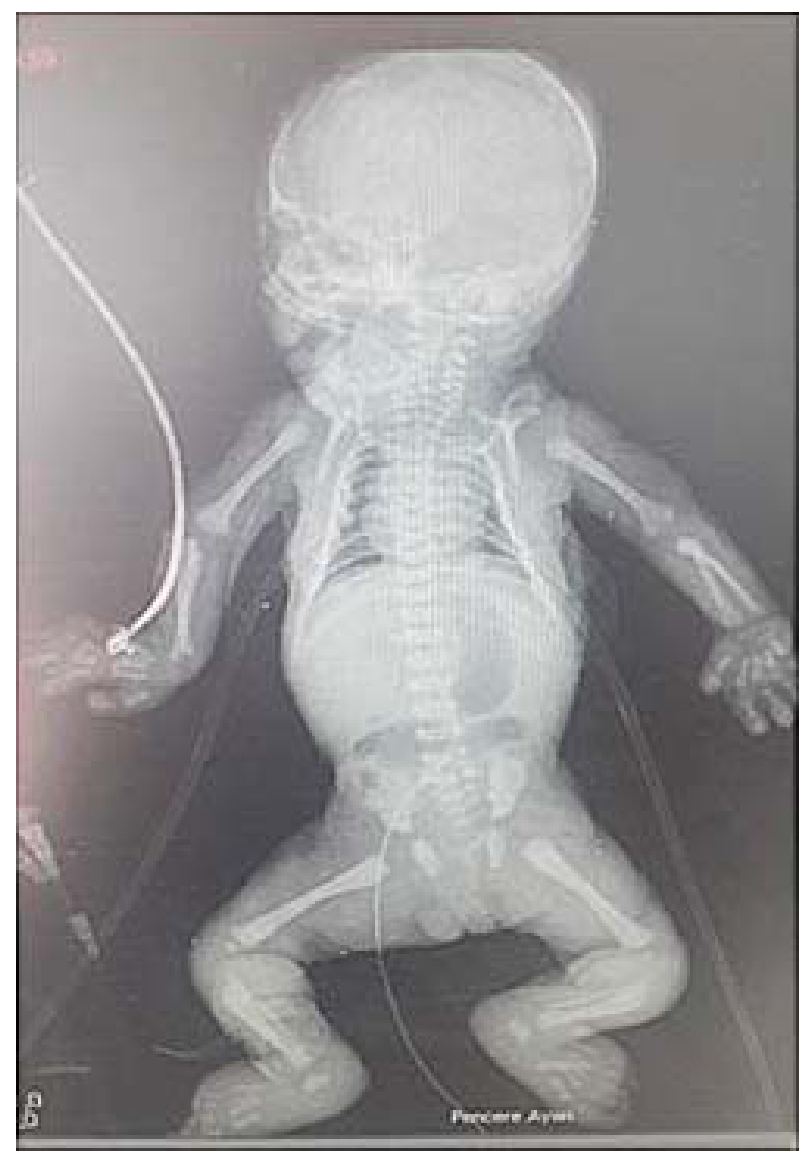

Sekil 2: Tüm vücut kemik grafisi pulmoner hipoplazi ve dar göğüs kafesini gösteren radyolojik görünüm.

Turner sendromunda daha önce bahsedilen tipik bulgular haricinde kardiyovasküler ve genitoüriner sistem başta olmak üzere pek çok sisteme ait doğumsal anomaliler eşlik edebilmektedir. Bu anomaliler içerisinde konjenital renal anomaliler TS'lu bireylerde normal populasyona göre dokuz kat fazla görülmektedir. S1klığ \%30-40 oranında bildirilmektedir $(7,8)$. En sik anomaliler \%20 oranda böbrek toplayıcı sistem anomalileri iken, $\% 10$ at nalı böbrek ve $\% 5$ oranında malrotasyon ve diğer pozisyon anomalileri görülür (9). Kromozom incelemesinde 45,X olan hastalarda renal malformasyonların sıklığının arttığı bildirilmektedir. Literatürde TS'da bilateral agenezi görülmemekte birlikte unilateral renal hipoplazi diğer böbreğin atrezik olduğu bir vaka bildirilmiştir $(9,10)$. Bizim olgumuzda da bilateral renal agenezi ve eşlik eden pulmoner hipoplazi mevcut idi.
Turner sendromunda kardiyovasküler anomali sıklığ $\%$ 20-40 arasında bildirilmektedir. $\mathrm{Bu}$ anomaliler, monozomi $\mathrm{X}$ olan hastalarda yapisal $\mathrm{X}$ anomalisi olanlardan daha fazla görülmektedir. Konjenital lenf ödemi ve yele boynu belirgin olan hastalarda kardiyovasküler anomaliler daha sıktır. Kardiyovasküler anomaliler tipik olarak sol kalbi tutmaktadır $(11,12)$. Mazzanti ve arkadaşları 594 TS'lu hasta ile yaptıkları çalışmada kardiyak malformasyonların sıklığını \%23 olarak bulmuşlar, \%12,5'inde bikuspid aort kapağ $1, \% 6,9^{6}$ unda aort koarktasyonu, \%3,2'sini aort kapak hastalığının oluşturduğunu bildirmişlerdir (13). Kapak anomalileri arasında en sik aort kapağ 1 anomalisi (\%24) ardından mitral kapak yetmezliği (\%21) bildirilirken, atrial septal defekt, ventriküler septal defekt, pulmoner venöz dönüş anomalileri ve hipoplastik sol kalp anomalileri de bildirilmektedir $(12,13)$.

TS'de kardiyak anomali sıklıği ve çeşidi ile karyotip arasında bir ilişki saptanmamış olup mozaik karyotiplerde obezite ve hipertansiyon sıklığ 1 monozomilere göre daha yüksek olarak bulunmuştur $(1,13,14)$. Turner sendromu şüphesi olan hastalar mutlaka kardiyak olarak incelenmelidir. Tanı konulduğunda ekokardiyografi ile değerlendirme yapılmalıdır. Bizim olgumuzda aort stenozu, aort koarktasyonu, patent duktus arteriosus saptandi. Mevcut anomalilerine ek olarak eşlik eden kardiyovasküler sorunları hastanın mortalitesini arttırd1. Erişkin yaşlarda TS'lu olgular infertilite sorunları, hipotiroidizm, otoimmun hastalıkları, osteoporoz, Y kromozomu mevcut ise artmış malignensi (gonadoblastom) riski, işitme kayıpları ve karaciğer fonksiyon testlerinde bozukluklar ile karşımıza gelir. Hipertansiyon, artmış aortik intima media kalınlığ 1 ve aortik disseksiyon normal populasyona göre TS'lu bireylerde daha s1ktır. Mentalite genellikle normaldir ancak nörokognitif işlevlerde bozuklukluk görülebilir $(11,14,15)$.

Kalp anomalisi, böbrek anomalileri, kistik higroması olan hastalarda TS ayırıcı tanıda düşünülmelidir. Şüphelenilen gebeliklerde ultrasonografi ve prenatal yöntemler ile tanı koymak mümkündür. Antenatal dönemde TS en sik abort nedeni kromozom anomalisi iken postnatal dönemde yaşamla bağdaşan bir kromozomal anomali olmasına rağmen hastamızda sebebinin ağır renal ve kardiyak anomaliler nedeniyle erken dönemde ölüm gerçekleşmiştir. Aileye genetik danışma verilmiştir. 


\section{KAYNAKLAR}

1. Nielsen J, Wohlert M. Chromosome abnormalities found among 34,910 newborn children: results from a 13-year incidence study in Arhus, Denmark. Human Genetics. 1991 May;87(1):81-3. PubMed PMID: 2037286.

2. Edward S. Tobias MC, Malcolm Fergusan-Smith. Essantial Medical Genetics. Wiley-Blackwell. 2011:80-1.

3. Turner HH. A syndrome of infantilism, congenital webbed neck, and cubitus valgus. Endocrinology 1938; 28:566.

4. Charles G. D. Brook PC, Rosalind Brown. Brook's Clinical Pediatric Endocrinology, 6th Edition. Wiley-Blackwell. 2009:124-54.9.

5. Price WH, Clayton JF, Collyer S, De Mey R, Wilson $J$. Mortality ratios, life expectancy, and causes of death in patients with Turner's syndrome. J Epidemiol Community Health 1986;40(2):97-102. PubMed PMID: 3746185 .

6. Liau J, Romine L, Korty LA, Chao C, White K, Harmon $S$, Ho Y, Hull AD, Pretorius DH. Simplifying the ultrasound findings of the major fetal chromosomal aneuploidies. Curr Probl Diagn Radiol. 2014 NovDec;43(6):300-16. PubMed PMID: 25239075.

7. Gorlin RJ CM, Hennekam RCM. Syndromes of the head and neck. In Oxford Monographs on Medical Genetics, No 42 4th edition Oxford, England. 2001; Oxford University Press: 57-62.

8. Gaertner S, Jeandidier N, Glasser L, Ohl J, Trinh A, Stephan D. Turner's syndrome: is there a risk of widespread vascular abnormalities? Clinical Endocrinology. 2016 Apr;84(4):634-5. PubMed PMID: 26303995.
9. Fanos V, Schena S, Dal Moro A, Portuese A, Antoniazzi F. Multicystic kidney dysplasia and Turner syndrome: two cases and a literature review. Pediatric Nephrology. 2000 Aug;14(8-9):754-7. PubMed PMID: 10955920.

10. Wax JR, Prabhakar G, Giraldez RA, Hutchins GM, Stetten G, Blakemore KJ. Unilateral renal hypoplasia and contralateral renal agenesis: a new association with 45,X/46,XY mosaicism. American Journal Of Perinatology. 1994 May;11(3):184-6. PubMed PMID: 8048981.

11. Bondy CA, Turner Syndrome Study G. Care of girls and women with Turner syndrome: a guideline of the Turner Syndrome Study Group. The Journal Of Clinical Endocrinology And Metabolism. 2007 Jan;92(1):10-25. PubMed PMID: 17047017.

12. Cramer JW, Bartz PJ, Simpson PM, Zangwill SD. The spectrum of congenital heart disease and outcomes after surgical repair among children with Turner syndrome: a single-center review. Pediatr Cardiol 2014; 35:253. PubMed PMID: 23933717.

13. Mazzanti L, Cacciari E. Congenital heart disease in patients with Turner's syndrome. Italian Study Group for Turner Syndrome (ISGTS). The Journal Of Pediatrics. 1998 Nov;133(5):688-92. PubMed PMID: 9821430.

14. Pinsker JE. Clinical review: Turner syndrome: updating the paradigm of clinical care. The Journal Of Clinical Endocrinology and Metabolism. 2012 Jun;97(6):E994-1003. PubMed PMID: 22472565.

15. Kriksciuniene R, Zilaitiene B, Verkauskiene R. The current management of Turner Syndrome. Minerva Endocrinol. 2016 Mar;41(1):105-21. PubMed PMID: 26878561. 